\title{
Editorial
}

\section{Smart energy materials}

Hydrogen has come out as a dominant part of clean energy component. Despite being the most abundant element in universe, passing the milestones of renewable hydrogen economy, from production to application is challenging. Great effort is required to extract the embedded hydrogen gas from other compounds, store and transport the same. Hydrogen found in organic compounds (hydrocarbons) can be separated by thermal processing known as reforming and it is the most commonly used method today. Electrolysis is a promising technology that uses electric current to split water into oxygen and hydrogen. Renewable energy sources like sun and wind can be used as clean energy source to produce hydrogen by water splitting. In future hydrogen could also be used as electricity, being an important energy carrier.

AEM2018, the 3rd International conference on advanced energy materials held at the University of Surrey, England, gathered eminent researchers, from over 50 countries to discuss the latest technologies that can be employed in advanced renewable energy projects. The special issue of AEM2018 is a collection of selected papers on topic hydrogen energy, presented at AEM2018. The highlights were hydrogen production, storage, transportation, photovoltaics, fuel cells and electrochemical systems.

It was a wonderful experience to work with the editorial and publishing team of International Journal of hydrogen energy (IJHE). On behalf of the AEM2018 organisers, I express our special gratitude to Prof. T. Nejat Veziroglu, the Founding Editor in Chief of IJHE and Dr. Ibrahim Dincer, special issue Editor in Chief, for their continuous support and inspiration to AEM conference. I also thank the scientific committee of AEM 2018 for their invaluable contribution in pre-evaluation and selection of the articles.

We look forward to meeting all our colleagues in the next AEM conference, which will be held at the University of Aveiro, Portugal from 15-17 July 2020 (https://www.advancednanomaterials-conference.com/anm-home/).

Elby Titus Center for Mechanical Technology and Automation (TEMA), Department of Mechanical Engineering, University of Aveiro Portugal E-mail address: elby@ua.pt Available online 5 March 2020

https://doi.org/10.1016/j.ijhydene.2020.02.047 0360-3199/@ 2020 Hydrogen Energy Publications LLC. Published by Elsevier Ltd. All rights reserved. 